\title{
OPMERKINGEN
}

OVER DE

ALPHABETTEN EN PROEVEN VAN OUD JAVAANSCH SCHRIFT,

voORKOMENDE IN DE BIJDRAGEN Deel VI, pag. 280 en volgg.

,

In eenige regelen ter inleiding van de alphabetten en schriftproeven, door de zorg van den Heer Keyzer overgenomen uit een handschrift van de Royal Asiatic Society te Londen, is voor nadere inlichting verwezen naar de beschrijving van dat handschrift, in mijn berigt over "Nog eenige bronnen voor de Taal-, Land- en Volkenkunde onzer Indische bezittingen, te Londen" (Bijdragen, Deel VI, pagg. 145-160).

Ofschoon nu bij die beschrijving reeds aangemerkt is, dat de bedoelde alphabetten "blijkbaar tot modellen gediend hebben voor plaat 21 van Raffles," en dat "het geheele bandje het voorkomen heeft, van opzettelijk te zijn bijeengebragt ten behoeve van het letterkundig gedeelte van Raffles' History of Java," zal het toch tot juiste waardering van de beteekenis der geleverde schriftproeven welligt niet overtollig zijn, te doen opmerken, dat die proeven, zooveel pl. I-VII betreft met nitzondering van de twee opschriften van ringen op pl. VII - niet door den schrijver van 't Londensch handschrift in haar geheel aan oudere handschriften of inscripties ontleend zijn, maar bestaan uit fragmenten uit dichtwerken van zeer jonge dagteekening $\left({ }^{1}\right)$, door hem in de van elders bekende oude schriftvormen overgebragt. Die proeven kunnen dus, met de transcriptie - als men het zoo noemen wil - in gewoon Javaansch schrift, die er in het handschrift onder stond, niets bewijzen voor de juistheid van de bijbehoorende alphabetten, en hebben op geene andere waarde aanspraak, dan als aanvulling en toelichting op die alphabetten (2).

(1) De 2de strophe van pl. I vindt men terug in de door mij uitgegevene Brâtå-joedå Måtjå-pat, VII, 1; de beide strophen van pl. III in hetzelfde werk, XXI, 1-2; die van pl. IV, ib. IV, 6-7.

(2) In den afdruk der transcriptie zijn de volgende feilen te verbeteren: I, 
Geheel anders is het gelegen met pl. VIII en IX. De eerste, in mijn exemplaar onderste boven geplaatst, geeft eene copie van de inscripties op den bekenden grooten lingga (sélå kalanangan, steenen symbool van voortteling) van Soekoeh, thans in het bezit van het Bataviasch Genootschap van Kunsten en Wetenschappen, dien men in Deel XIX der Verhandelingen van dat genootschap, verschenen in 1843, door Dr. van der Vlis afgebeeld, beschreven en verklaard vindt. Zijne lezing schijnt, even als die van onzen onbekenden schrijver, hoogst willekeurig, en de vertaling genoegzaam uit de lucht gegrepen. De groote overeenstemming, die nogtans tusschen beide uitleggers bespeurd wordt, ofschoon van der Vlis geene andere voorlichting had dan van den Radèn Ngabèhi RåNGGå WARsı̃å van Soerakarta, en ons handschrift, waarschijnlijk van Madura afkomstig, reeds lang te voren door Raffles naar Europa moet zijn vervoerd, geeft aanleiding tot het vermoeden, dat omtrent de beteekenis der inscripties eene inlandsche overlevering bestaat, die wel eenigen grond van waarheid hebben mag. In de lezing van de twee regels, die het hoofddoel der inscripties uitmaken, bestaat geen ander wezenlijk verschil, dan dat van der Vlis voor het achtste teeken van den eersten regel leest as in plaats van of, Voor het eerste woord, uit de drie eerste teekens bestaande, heeft van der Vlis op

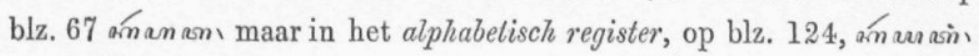
denkelijk beiden druk- of schrijffouten voor ḿman asi even als bij onzen schrijver in de herhaling op blz. 9 (288), r. 3 : amánaì voor ánanain zoo als zijne transcriptie heeft. In die herhaling is ook in $\mathrm{r}$. 5, tusschen qoranis en áras het woord amais uitgevallen. - In de verklaring van diezelfde inscriptie - waarvoor men bij van der Vlis ook het Alphabetisch register dient te raadplegen - is het voornaamste onderscheid, dat van der Vlis den tveeden regel het eerst leest, en aldus uitlegt: air

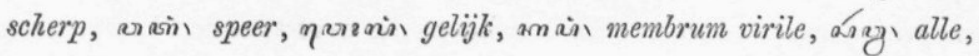
am die, ij) tegenkomen (acutum pudendi virilis simile est acuto hastae. Omnes quibus occurrit); waaraan zich dan aansluit het eerste woord van regel 1: ánamiò vlugten, enz. Voorts wordt ánazasai door onzen

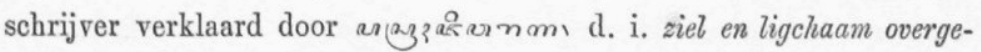
ven, natuurlijk met betrekking tot de lijdende partij; door van der Vlis waarschijnlijk ten gevolge van misvatting van dezelfde Javaansche om-

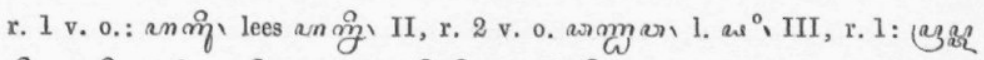
มำ ๆ

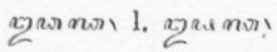


schrijving, door leven en ligchaam overstorten, wat dan van het handelend deel te verstaan is. - En voor án errm naain zoo als onze schrijver heeft, heeft van der Vlis án niet, as ontbreken, mma gunst, ais die, enz. (Neque illa quẩ velhitur, caret favore).

In de lezing van het jaartal op het voetstuk stemmen beiden overeen; ook daarin, dat zij de kortere inscriptie onder het jaartal als eene omschrijving daarvan in woorden verklaren, maar verschillen aanmerkelijk in de lezing en verklaring van die woorden in het bijzonder.

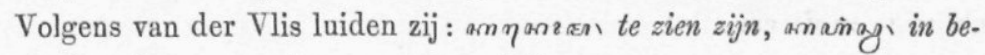

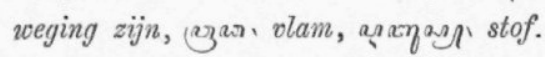

Pl. IX, a en b, van onze fac-simile's bevat als proeve de eerste blz. uit den Falak Boedha - d. i. Boedhistische kalender: een naam, die er echter buiten twijfel eerst later aan gegeven is - die in 't Londensch handschrift ruim 70 blz. beslaat, en daarin uit een ouder handschrift in het oorspronkelijk karakter moet zijn overgeschreven. Reeds bij de eerste inzage kwam het mij twijfelachtig voor, of het gewoon Javaansch schrift, aan het begin van dat stuk toegevoegd, wel eene transcriptie zijn kon; maar het had toch ook niet het voorkomen van eene vertaling te zijn, en bij gemis van een alphabet van dien schriftvorm ontbrak mij toen de tijd, om de zaak nader te onderzoeken. Thans is mij gebleken, dat het inderdaad half het een en half het ander, of, zoo men wil, het een zoo min als het ander is; want de schrijver heeft over het algemeen het oorspronkelijke slechts in Javaansche letters overgeschreven, hier en daar echter het Kawi in nieuw Javaansch vertaald of omschreven, maar in beiden, naar het schijnt, meermalen misgetast $\left({ }^{1}\right)$. Ik laat daarom hier achter eene letterlijke transcriptie van den tekst volgen, zoo als ik meen dien te moeten lezen, voorafgegaan door die van 't alphabet, dat ik er uit afgeleid heb, en afzonderlijk wedergeef. De teekens, die daar tusschen haakjes geplaatst zijn, heb ik in het klein fragment van den tekst niet gevonden. Enkele zijn mij ook min of meer twijfelachtig gebleven, en slechts bij gissing bepaald. De lithographische uitvoering kan zeker veilig worden toevertrouwd aan den Heer Lankhout te 's Hage, die buiten de hier besprokene fac-simile's, uit hetzelfde handschrift de geheele Bharatajoedha Kavi, zijnde 136 blz. zeer fijn schrift, in steendruk gebragt

${ }^{1}{ }^{1}$ Als drukfouten zijn denkelijk te beschouwen: r. 3: a

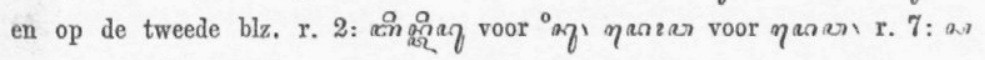

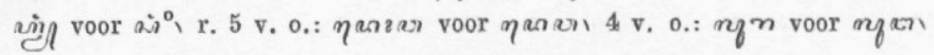


heeft, en, zoover ik tot nu toe heb kunnen nagaan, daarin uitnemend geslaagd is.

Aan eene vertaling zal ik mij maar niet wagen, daar deze, om verstaanbaar te zijn, eene omslagtige uitweiding over inlandsche astrologie behoeven zou, die hier minder op hare plaats zou zijn. Wie met de inrigting van zulke werken eenigermate bekend is, zal in de Javaansche omschrijvingen van den zamensteller van het handschrift wel eenige verklaring vinden, die evenwel geen onbepaald vertrouwen schijnt te verdienen.

Batavia, Augustus 1863.

A. B. COHEN STUART.

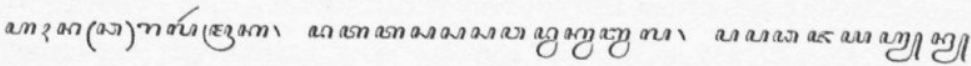

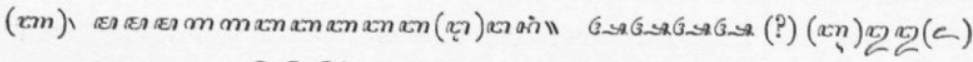

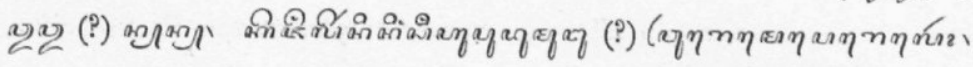
ang"

ๆ

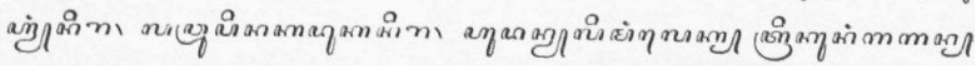

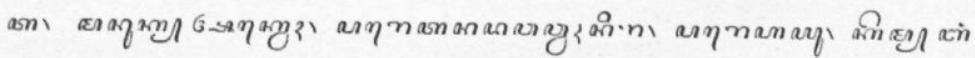

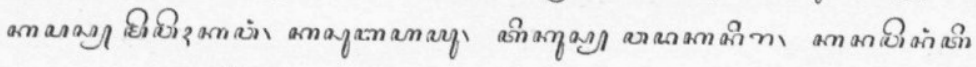

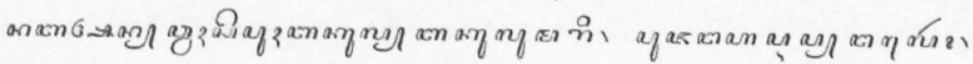

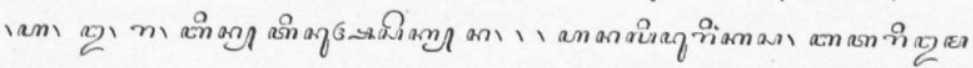

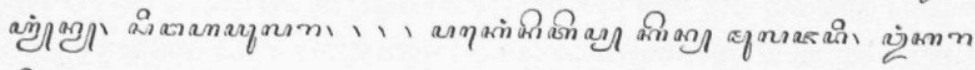

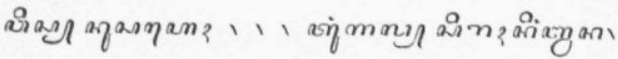

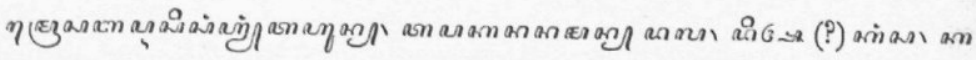
थก के

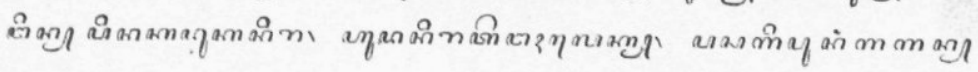




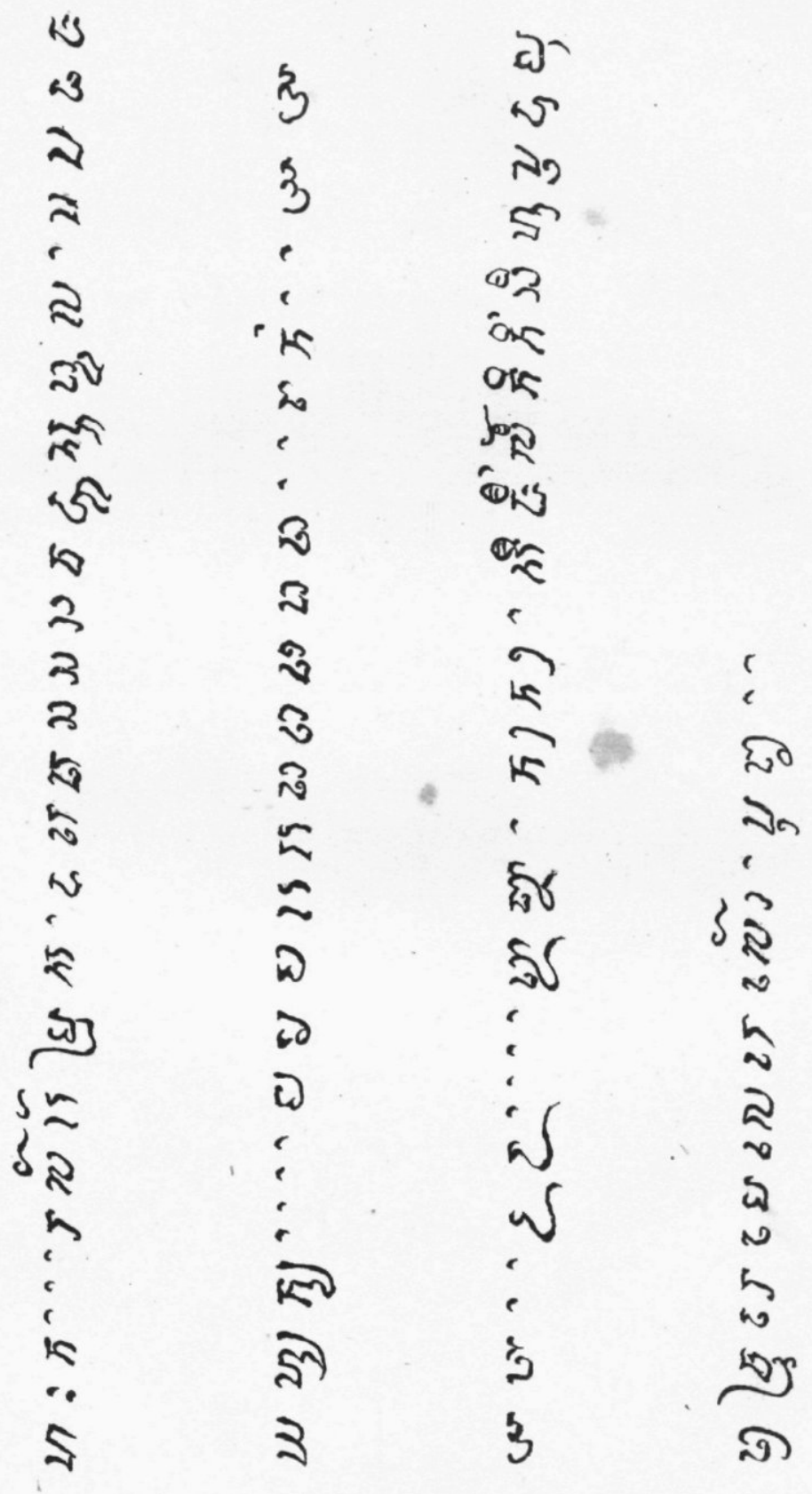




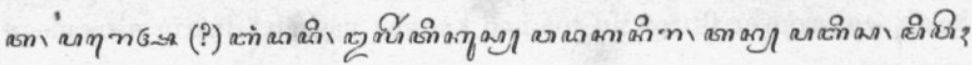

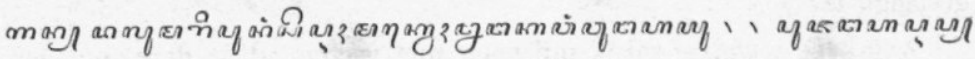

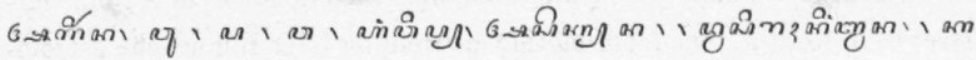

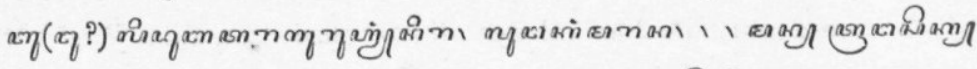

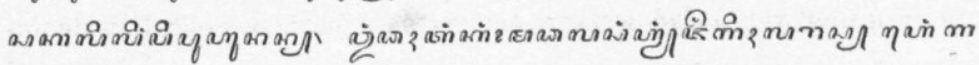
arglaszan? 1.1 
De Japansche Traktaten met Nederland, Rusland, Engeland, de Vereenigde Staten en Frankrijk in 1858 te .Jedo gesloten.

Fac-simile van den Japanschen Tekst.

\section{The Japanese Treaties,} concluded at Jedo in 1858 with the Netherlands, Russia, Great-Britain, the United States and France. Fac-simile of the Japanese Text.

'S GRAVENHAGE, MARTINUS NIJHOFF, 1862.

Den aard van dit werk kan men niet beter doen uitkomen, dan door de opneming van het kort berigt, dat het fac-simile voorafgaat.

Daar het voor eene degelijke beoefening der Japansehe taal eene behoefte is ook voorbeelden van den thans in Japan gebruikelijken officielen stijl te bezitten, heeft de uitgever op aanraden van schrijver dezes tot de uitgave besloten van een facsimile van den Japansehen tekst der in 1858 te Jedo met de vreemde mogendheden gesloten traktaten, die daar onder den titel Ansei Tsutsinoye M'ma dế-yak sjo-men ${ }^{1}$ in den zomer 1859 door den druk is uitgegeven.

Heeft men er vroeger prijs op gesteld, dat de Chinesche tekst der in 1842-44 met China gesloten verdragen tegelijk met de Engelsche of Fransche redactie in het Chinese Repository opgenomen en door afzonderlijke overdrukken met den titel Treaties of Peace meer algemeen verkrijgbaar gesteld werd, eene uitgave van den Japanschen tekst der thans in werking zijnde Japansche traktaten en tolreglementen zal den beoefenaar der Japansche taal voorzeker evenzeer welkom zijn.

Maar het is niet alleen de aan officiéle stukken eigene stijl, die onze aandacht verdient; ook als proeve van het Japansche snelschrift komen deze oorkonden in aanmerking, daar het fac-

\section{'安政戊午條絇書面}


simile ten opzigte der penceelvoering bij de Jedosche uitgave niet achterstaat.

De vervaardigers van dit fac-simile waren, toen zij dit werk verrigtten, wel is waar, nog niet in Japan geweest; maar het afschrift dat zij leverden is van dien aard, dat geen Japannees aarzelen zal het voor goed landsschrift te laten doorgaan; en dit schijnt ons voldoende.

De oorkonden; in dezen bundel vervat, zijn:

1. Het Traktaat tusschen Nederland en Japan, gesloten te Jedo, den $18^{\text {den }}$ Augustus 1858, met de Regulatiën onder welke de Nederlandsche handel in Japan zal gedreven worden ${ }^{1}$. (Olankok dế-yak narabini mitsugi-nori).

Van dit stuk zal nog afzonderlijk de Japansche tekst met voluit geschreven Chinesche karakters (Sung pan) en Japansch Katakana worden uitgegeven. De lezing van den tekst zal daarbij volledig opgegeven en eene woordelijke Nederlandsche vertaling er aan toegevoegd worden.

2. Het Traktaat tusschen Rusland en Japan gesloten te Jedo, den $19^{\text {den }}$ Augustus $1858^{2}$. (Rosia-kok deô-yak).

3. Het Traktaat tusschen Engeland en Japan gesloten te Jedo, den $26^{\text {sten }}$ Augustus $1858^{3}$. (Inkiri-kok dế-yak).

4. Het Traktaat tusschen Amerika en Japan gesloten te Jedo, den $29^{\text {sten }}$ Augustus $1858^{4}$. (Amerika-kok dế-yak).

5. Het Traktaat tusschen Frankrijk en Japan gesloten te Jedo,

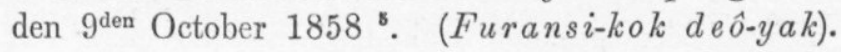

$\mathrm{Om}$ de vergelijking dezer oorkonden zoowel onderling als met de woordelijke vertaling, die afzonderlijk zal gegeven worden, gemakkelijk te maken, heeft men bij den Japanschen tekst met Romeinsche cijfers het nommer van ieder artikel, en met Arabische dat van de alinea's doen voegen.

De vervaardigers van het fac-simile zijn de heeren R. J. DE SAINT AULAIRE, J. A. BUDDINGH en W. P. GROENEVELDT,

1 阿蘭陀國條絇並程 則

2魯西严國條約

3 英吉利國條絶

4亞墨利加國條約

与佛蘭西國條約 
Nederlanders, die zich, op grond van beschikkingen, door vroegere Ministers yan Koloniën genomen, onder de leiding van den hoogleeraar J. HOFFMans, op de beoefening der Chinesche en Japansche talen hebben toegelegd, ten einde later als translateurs en tolken den lande te kunnen dienen. De eerstgenoemde heer bevindt zich thans als Japansch tolk te Nagasaki, de beide anderen zijn te Canton, om meer bijzonder den Canton-tongval te bestuderen.

Door de heeren groeneveld en saint aulaire is gedurende den laatsten tijd van hunne studie te Leiden nog een ander even belangrijk als nuttig werk verrigt; wij bedoelen het

\section{- MaNUAl OF CHINESE RUNNING-HAND WRITING}

especially as it is used in Japan, compiled from original sources by R. J. DE SAINT AULAIRE and w. P. GRoeneveldT (Printed for the authors). Sold by G. M. van Gelder, Amsterdam, 1861, 4ㅇ 173 bladz.

Kenmerkt zich dit Manual door zijne inrigting als een gemakkelijke sleutel tot het zoo moeijelijk te ontcijferen Chinesche snelschrift, zoo als het in Japan in gebruik is; de technische uitvoering, het werk van den Heer Groeneveldt, is van dien aard, dat de voornaamste leden van het Japansche gezantschap, hetwelk in 1862 Nederland bezocht heeft, het praedikaat van "mottomo kireinal" ('t is overheerlijkl) daaraan hebben toegekend.

Daar een werk van zoo specialen aard, als dit Manual, minder algemeen bekend wordt, meenen wij, met het oog op het belang der zaak, vit zijne inleiding datgene te mogen overnemen, wat het ontstaan en doel van dit Nederlandsch voortbrengsel van beoefening van oostersche talen toelicht.

\section{Uittreksel wit de Inleiding tot het Manual.}

"Toen wij het werk opvatten, dat wij thans aan onze medebeoefenaars der Chinesche en Japansche talen aanbieden, hadden wij geen ander oogmerk, dan ons zelven een middel te verschaffen om zoo goed mogelijk met het Chinesche snelschrift bekend te worden. Nadat wij ons eenigen tijd op de beoefening dier talen hadden toegelegd, bleek ons de noodzakelijkheid dezer kennis, en wij gevoelden de behoefte aan een gids, die ons snel en zeker tot deze kennis zou leiden. Een zulke niet bestaande, 
bleef ons geen andere keuze dan, hetzij uit de verscheidene voorbeelden van snelschrift een aantal van de meest gebruikelijke karakters uit te zoeken en zoo allengs ons oogmerk te bereiken, dan wel zelven een handboek zamen te stellen, dat voor goed in onze behoefte zou voorzien.

“De eerste weg zoude, naar wij begrepen, veel tijd en moeite gekost hebben zonder geheel en al te voldoen. Vormen, aan het geheugen ontgleden, zouden ons tot tijdroovend opzoeken genoopt hebben, dat soms zelfs vruchteloos zijn kan. Wij sloegen derhalve den anderen weg in en gingen aan het werk. Toen het gedaan was, begrepen wij, dat het ook anderen van nut zou zijn, en besloten dus het door den druk uit te geven.

“Onze geachte leeraar, Prof. Dr. J. Hoffmann, die ons tot het ondernemen van dezen arbeid had aangespoord, stelde gaarne al wat hij aan bouwstoffen daarvoor bezat ter onzer beschikking en stond aan ons het Japansch encyclopedische woordenboek Manbô sets-yô fu-ki $s \hat{o}^{1}$ af, om de daarin vervatte opgaven van het snelschrift in ons handboek op te nemen. Dit werk heeft dan ook tot grondslag verstrekt van onzen arbeid, terwijl nog een aantal moeijelijke vormen van Chineesch snelschrift uit een ander soortgelijk woordenboek het Man-dai sets-yô zi-rin bô-zô ${ }^{2}$, ontleend is.

“Wij kunnen deze gelegenheid niet laten voorbij gaan, zonder erkentelijk te doen uitkomen, dat, welke dienst door onzen arbeid ook an de wetenschap mogt worden bewezen, wij een groot gedeelte der verdiensten aan Prof. H. moeten toekennen, die ons de beginselen, waarop dit schrift gebaseerd is, heeft blootgelegd, ons ruimschoots van bouwstoffen voor onzen arbeid heeft voorzien, en ons in menig moeijelijk geval met raad bijstond.

"Bij de bewerking van dit handboek kwam het er vooral op an eene methode te volgen, die reeds van den beginne af den waarborg in zich droeg, dat de vormen van het snelschrift, met de ter yerklaring daarnaast geplaatste standaardvormen werkelijk overeenstemmen en dat er ten dezen opzigte geen misslag begaan werd. Wij hebben het eerstgemeld woordenboek, dat, zoo als doorgaans de boeken van China en Japan, slechts op eene zijde van het papier gedrukt is, geheel aan stukken gesneden en de

1 萬寶節用富貴藏

? 萬代節用字林賏藏

VII. (XI.) 
aldus verkregen woorden ten getale van omtrent 45,000 naar het voor ons werk beraamd stelsel in klassen verdeeld en vervolgens behoorlijk geordend en opgeplakt, waarbij de voorko. mende doubletten werden uitgescheiden. De aldus verkregen bouwstof heeft vervolgens als een stelselmatig geordend origineel gediend, waarnaar het Manual werd op steen gebragt. Daar de verklarende standaardvormen steeds met den cursiefvorm verbonden bleven, kon ten opzigte ter wederkeerige betrekking van beide vormen geen mislag plaatsgrijpen.”

Het Manual is in twee deelen gesplitst. In het eerste zijn de karakters naar het aantal trekken van den standaardvorm geordend, in het tweede naar de karakteristieke trekken van den cursiefvorm, volgens eene methode, door de vervaardigers in hunne inleiding uiteengezet.

Wij moeten instemmen met den wensch, waarmede de schrijvers hunne inleiding besluiten.

"In conclusion we hope that this work may be to others what it has been to us: - a key to the rich store of Japanese and Chinese textes written in running-hand character." Leiden, 1862.

J. HOFFMANN. 